\title{
CLINICAL ASSESSMENT OF NEUROMUSCULAR TRANSMISSION
}

\author{
J.P. PAYNE \\ Research Department of Anaesthetics, Royal \\ College of Surgeons of England, London WC2, \\ St Peter's Hospitals, London WC2 and the \\ London Hospital, London E1

\section{R. HUGHES*} \\ Research Department of Anaesthetics, Royal \\ College of Surgeons of England, London WC2 \\ and St Peter's Hospitals, London WC2
}

\section{Introduction}

The concept of neuromuscular transmission as a separate physiological entity was introduced by Claude Bernard in 1851 when he demonstrated by means of curare that the junction between nerve endings and muscle fibres possessed unique properties. The logic and simplicity of Bernard's experiments have not been surpassed by more modern methods and they still offer a convenient and relatively inexpensive means of screening new drugs with a possible action at the neuromuscular junction. Bernard's studies with curare focused attention on its peripheral actions and its therapeutic possibilities were soon recognised. By 1858 the drug had already been used in the management of tetanus and shortly thereafter albeit with less justification it had been employed in the treatment of a variety of diseases including chorea, epilepsy and hydrophobia.

Curare continued to be used intermittently throughout the remainder of the 19th century and beyond without any proper understanding of its action and without any real evidence of beneficial effect. However where it was used to advantage was in the developing sciences of physiology and pharmacology where the use of such pharmacological techniques as had been described by Bernard had become an essential component in the interpretation of physiological phenomena. None were more adept in the exploitation of these techniques than Henry Dale and his colleagues but it was 1934 before the first definitive evidence was published that established the chemical transmitter acetylcholine as the physiological link between the nerve-endings and the muscle fibres (Dale \& Feldberg, 1934; Dale, Feldberg \& Vogt, 1936).

Subsequently in a series of well planned experiments Dale and his group succeeded in defining the

\footnotetext{
*Present address: Pharmacology Department, The Wellcome Research Laboratories, Langley Court, Beckenham, Kent BR3 3BS
}

pattern of neuromuscular transmission and in so doing laid the foundations for the development of a new pharmacological approach to the management of anaesthesia for thoracic and abdominal surgery.

\section{Mechanism of neuromuscular transmission}

Understanding has been helped by the application of modern technology which has enabled the individual constituents of the neuromuscular junction to be identified so that its anatomical structure is now well demarcated. Essentially, when a motor nerve reaches the muscle it supplies, it divides into a series of myelinated axons which in turn break down into branches to supply groups of from 5 to 300 muscle fibres. These branches lose their myelin sheath as they approach the muscle and further sub-divide into fine terminals which end in close approximation to highly localised and specialised areas of the muscle membrane arranged in discrete folds to form the postsynaptic membrane. But even at this stage there is no direct contact between nerve and muscle; they are separated not only by the pre-synaptic membrane which encloses the nerve ending and the postsynaptic muscle membrane but also by a distinct extracellular gap which itself is partitioned by a basement membrane.

The physiological pattern of events at the neuromuscular junction can now be described. The chemical transmitter acetylcholine is formed and stored in the nerve terminal by the action of the enzyme choline acetyltransferase on the simple ammonium quaternary base choline. Storage of acetylcholine occurs as discrete packages or quanta and up to 200,000 such quanta may be accumulated, enough to react to several thousand impulses although only a small fraction of that number is immediately available to respond to individual impulses. The amount of acetylcholine released 
during repeated nerve stimulation is determined by a series of factors including the quantity present at the time of stimulation, the extent of previous activity and the concentration of calcium ions. The rate at which acetylcholine can continue to be released reflects the balance between the extent to which it can be mobilised from the main stores and the speed at which it is utilised. Once released acetylcholine diffuses across the extracellular gap to occupy the receptor areas on the post-synaptic muscle membrane. The process of occupation stimulates an electrical change and the resting potential of the endplate becomes less negative. If the electrical change is great enough a critical threshold is reached and an action potential is produced on the surface of the adjacent muscle membrane. This in turn provokes a muscle contraction the strength of which is related to the number of motor units stimulated.

A distinction needs to be made between the mechanism responsible for the end-plate potential and that which brings about the action potential. The end-plate potential is caused by the occupation of the specific receptors by acetylcholine and is not propagated. The action potential is elicited by the increase in membrane permeability provoked by the endplate potential. The change in membrane permeability results in a rapid movement of sodium into the cell across the cell membrane and a subsequent loss of potassium. Normally a negative potential of around $70 \mathrm{mV}$ is maintained within a resting cell relative to that on the external surface of the membrane by the active exclusion of sodium ions. When this mechanism is disturbed by the action of acetylcholine on the end-plate the shift in ionic balance causes the membrane potential within the cell to fall to zero and then to overshoot so that the interior of the cell becomes positive. This electrical change propagated from cell to cell and described as the depolarisation process produces the muscle contraction. Repolarisation must occur before the muscle can contract again.

Thus neuromuscular transmission will be interrupted if the synthesis of acetylcholine is disturbed, if it fails to be released at the nerve terminals, if that which is released is prevented from occupying the receptors interposed between the nerve endings and the muscle fibres or if the muscle membrane in immediate proximity to the motor end-plate is unable to regain its excitability. In practice block of neuromuscular transmission is achieved with two groups of drugs; the first competes with acetylcholine for access to the motor end-plate and the second produces a persistent depolarisation so that the muscle membrane becomes electrically inexcitable.

Initially the investigation of neuromuscular blocking drugs attracted little interest, despite the enthusiasm of clinicians like Ranyard West (1932) who attempted a quantitative assessment of curare for the treatment of spasticity in neurogenic disease and
A.E. Bennett (1941) who used the drug to prevent the traumatic complications of shock therapy in psychiatry. It was not until Griffith and Johnson (1942) used curare as a skeletal muscle relaxant for major abdominal surgery that its place in medicine became established. Its use in surgery was a major step forward; not only did it revolutionise anaesthetic practice by removing the need for deep anaesthesia it also stimulated a new interest in neuromuscular transmission as pharmacologists realised the possibilities of this clinical development.

\section{Quantitative assessment of muscular function}

Ranyard West's (1932) assessment of curare was probably the first quantitative evaluation of neuromuscular function in man and was based on a device designed for measuring the force required to extend the leg at the knee joint. The apparatus was designed to be used on a sedentary patient and consisted of two flat boards of suitable dimensions. The first was applied to the anterior aspect of the thigh so that it projected beyond the knee joint at which point the second board was hinged and suspended along the anterior surface of the leg. The degree of extension, which was provided by a spring balance attached to the ankle, was assessed before and after the injection of curare by measuring the force required to produce the extension determined by the angle between the boards.

Such a technique though useful in the assessment of spastic states was scarcely applicable to normal healthy volunteers so that when Paton \& Zaimis (1948) introduced decamethonium as a depolarising neuromuscular blocking agent suitable for clinical use the effects of the drug were studied on ventilation and on muscle tone (Organe, Paton \& Zaimis, 1949).

A similar approach was adopted by Mushin and his colleagues in the first clinical trial of gallamine (Flaxedil) undertaken in the United Kingdom (Mushin, Wien, Mason \& Langston, 1949) but neither group described their techniques in detail. Both these studies attempted to relate muscular power to respiratory effort. Organe and his colleagues compared the effect of the drug on vital capacity with that on hand-grip strength, leg-raising ability and abdominal muscle tone, while Mushin's group compared activity with minute ventilation.

On the basis of preliminary experiments Mushin and his colleagues concluded that in conscious volunteers the contracting power of muscles was best measured by mechanical devices. In the case of the hand muscles a dynamometer was used with a pointer which moved over a scale graduated appropriately. For measuring the ability of the rectus muscles to contract a spring-loaded pad was adjusted in position on the abdomen with the volunteer supine and the 
knees firmly strapped down. When leg-raising was attempted the recti became taut and the pad was displaced upwards against the spring which in turn moved a pointer over a scale.

These relatively simple techniques have the advantages that they are easy to use, they can be adapted to suit different circumstances and the equipment can be improvised from readily available appliances. For example, Bodman (1952) assessed hand-grip strength by the ability of a volunteer to compress a rubber bulb filled with water and connected to a mercury manometer. Because of the relative incompressibility of water a single compression of the bulb was sufficient to raise the mercury column to produce a reading. The main problem was that intervals of two minutes between compressions were needed to avoid fatigue.

The general disadvantage of such techniques is that they depend on voluntary effort so that the subjects need to be conscious with the corresponding problems associated with such factors as adrenaline release and carbon dioxide retention. In addition the results can only be interpreted as indicating a trend rather than providing fully quantitative data. Nevertheless the use of these techniques did demonstrate the relative resistance of the respiratory muscles to neuromuscular block and made it possible to identify different degrees of muscle sensitivity to the blocking drugs.

Since the respiratory effects are of paramount importance in the assessment of neuromuscular blocking drugs it is not surprising that the measurement of such effects was a prominent feature of the early studies and certainly in anaesthetic practice alterations in pulmonary ventilation were regarded as the most satisfactory index of change in the degree of neuromuscular block (Brennan, 1956). However the distinction needs to be made between techniques suitable for conscious volunteers and those that can be used in anaesthetised patients.

Tests of respiratory function such as the determination of forced expiratory volumes and vital capacity demand the active co-operation of the subject and are therefore suitable only for use with conscious volunteers. In most instances investigators have endeavoured to study a range of variables one of which could be used as the end-point. In one such study, by Johansen, Jorgensen \& Molbech (1964) the experiments involved the measurement of four separate functions; head-lift and hand-grip were compared to either maximal inspiratory and expiratory flows or to maximal inspiratory and expiratory pressures. The degree of depression of respiratory muscle power and hand-grip strength was determined when the ability to raise the head was nearly or completely abolished by tubocurarine. In these experiments the strength of head-lift was measured by means of a strap placed around the forehead attached to a strain- gauge dynamometer and registered by an automatic measuring bridge. The hand-grip strength was also determined by a hand dynamometer and recorded in the same way as the head-lift. Maximal inspiratory and expiratory flows were measured on a direct reading gas flowmeter. Maximal inspiratory pressure after maximal expiration and maximal expiratory pressure after maximal inspiration were measured on a simple mercury manometer. The weakness of this approach is that volunteers have to be trained before performing the respiratory function tests if reliable results are to be obtained.

Such techniques are manifestly unsatisfactory in anaesthetised patients and most studies in this field have been restricted to an analysis of the changing respiratory pattern in response to neuromuscular blocking drugs. In one of the earliest studies by Brennan (1956) the reservoir bag of a standard Boyles' anaesthetic machine was inserted through the neck of a sealed aspirating bottle which was connected by widebore tubing to a Benedict-Roth recording spirometer. A continuous record was obtained from which could be derived the respiratory rate and the tidal and minute volumes as required. An alternative method is to substitute the recording spirometer for the rebreathing bag in a closed circle anaesthetic system.

Such methods have the disadvantage that the evidence of neuromuscular block can only be presumptive on the basis of a developing muscle weakness and that a quantitative assessment of the failure of neuromuscular transmission is virtually impossible. It was for these reasons that more precise and more specific methods of measuring interference with neuromuscular transmission were developed. Currently the most widely used method for assessing neuromuscular blockade in màn.depends on the measurement of the force of skeletal muscle indirectly evoked by the stimulation of the associated motor nerve.

\section{Quantitative assessment of neuromuscular trans- mission}

\section{Single twitch response}

The first detailed account of such a method suitable for the accurate assessment of neuromuscular blocking drugs in man was published by Mapleson \& Mushin in 1955. The method was based on that described by Bigland \& Lippold (1954) for the determination of the tension developed in the small muscles of the thumb supplied by the ulnar nerve when square wave pulses were applied to the nerve at different frequencies. For reasons of convenience in the operating room Mapleson \& Mushin preferred to stimulate the median nerve at the wrist and measured the contraction of the small flexor muscles of the 
thumb when the nerve was stimulated by means of a 'multiwick' electrode placed on the skin over the nerve. Sub-maximal stimuli of $9 \mathrm{~ms}$ duration at a frequency of $50 \mathrm{~Hz}$ were applied for $1.2 \mathrm{~s}$ every $6 \mathrm{~s}$ and the resultant contractions were recorded with an ink writer through a mechanically operated system. Poulsen \& Hougs (1957) also used sub-maximal tetanic stimuli of the median, tibial and peroneal nerves in their study of the effects of various curarising drugs in conscious volunteers."

A somewhat different approach had been adopted earlier by Thesleff (1952) who measured the twitch response of the ulnar fingers of the hand in anaesthetised patients when supramaximal stimuli were applied to the ulnar nerve at the elbow and this technique was utilised by Payne \& Holmdahl (1959) when they demonstrated the development of tachyphylaxis in man after repeated doses of suxamethonium. For this purpose a supramaximal stimulus provided by a square wave pulse of $0.5 \mathrm{~ms}$ duration was applied at $10 \mathrm{~s}$ intervals through a surface electrode placed over the ulnar nerve in the vicinity of the elbow joint. The voltage required ranged from 70 to 100 volts and it was possible to maintain this type of stimulation for several hours without any obvious ill effects. The contractions were recorded through a metal strip fixed to the two ulnar fingers of the hand and connected through a pivot to a flat steel spring myograph suitably amplified to produce an ink tracing on a rotating drum. Subsequently a more convenient method of measuring the twitch response was described by Katz (1965) who measured the contraction of the adductor pollicis muscle of the thumb following supramaximal stimulation of the ulnar nerve at the elbow or the wrist. Katz studied the electrical and mechanical responses of skeletal muscle to nerve stimulation as well as the integrated abdominal electromyogram and concluded that the mechanical response of the muscle to nerve stimulation was the most accurate, convenient and useful guide to the effects of neuromuscular blocking drugs.

Later work by Gissen \& Katz (1969) has demonstrated that the single twitch is a less sensitive index of neuromuscular transmission than is the response to tetanic stimulation in the frequency range $20-200 \mathrm{~Hz}$.

\section{Train of four}

In an attempt to overcome the relative insensitivity of single twitch measurements Ali, Utting \& Gray (1970) introduced the concept of 'the train of four' for the assessment of neuromuscular block. The method is based on the fact that under conditions of partial neuromuscular blockade it is possible to show that if a steady state of twitch height is obtained at a particular frequency of stimulation a change to a higher frequency lowers the twitch height and a new lower steady state is usually attained after five stimuli at the faster rate. In practice Ali et al. (1970) recommend the use of trains of four stimuli at a frequency of $2 \mathrm{~Hz}$ repeated at $10 \mathrm{~s}$ intervals.

This reduction in twitch height in response to repetitive nerve stimulation was first used clinically by Roberts \& Wilson (1969) who used a train of four stimuli at a frequency of $4 \mathrm{~Hz}$ in myasthenic patients to assess the progress of the disease and to determine the effects of treatment.

The main advantage claimed for the 'the train of four' is the fact that a clinical assessment can be carried out at any time without the need to refer to a control period. There can be no doubt that this is a particularly useful attribute in the clinical field when, for example, the diagnosis of residual block may be in doubt or when an assessment of the response to treatment is needed. However in the quantitative evaluation of neuromuscular block it seems unlikely to offer any advantages over the single twitch response and from that aspect it has yet to prove its value.

\section{Tetanic response}

The relative lack of sensitivity in the single twitch response has been a source of anxiety to many investigators and led Cookson \& Paton in 1969 to comment that 'the mere recording of muscle twitches under clinical conditions is not likely to yield much further dividends. On the other hand careful study of tetanic and post-tetanic responses under different conditions of block would be very helpful.' Despite the uncertainty about the value of the single twitch it continued to be widely used. Some years were to elapse before a direct simultaneous comparison between tetanic and single twitch responses demonstrated that after the administration of neuromuscular blocking drugs the tetanic and single twitch contractions follow a different pattern of behaviour. In some instances the difference is qualitative as well as quantitative. Further in the presence of marginally adequate neuromuscular transmission tetanic fade increases with the frequency of stimulation even though the twitch response is unaffected. Thus the use of high frequency tetanic stimuli may reveal a failure of transmission not apparent with single twitch contractions. Tetanic fade is defined as the failure to sustain the square wave form of the tetanic contraction in response to tetanic stimulation. As recovery from neuromuscular blockade proceeds tetanic fade progressively disappears until the response is fully sustained. This led to the suggestion that if the maximum benefit was to be derived from studies of neuromuscular blocking drugs both tetanic and single twitch responses should be recorded (Sugai, Hughes \& Payne, 1973). Since then these authors have carried out a series of such studies undertaken on patients about to undergo elective 
surgery and from whom informed consent had been obtained. It is now considered that the tetanic response gives a more accurate assessment not only of the depth but also of the time course of neuromuscular blockade than does the single twitch. Moreover the tetanic response is more physiological since breathing and the movement of skeletal muscles are activated by trains of stimuli rather than by single shocks.

Throughout their studies the small adductor muscles of the thumbs supplied through the ulnar nerve have been used and the investigators have now developed a standard technique for the clinical evaluation of neuromuscular drugs. Adduction of the thumbs is measured by strain-gauge transducers mounted in the hands as first described by Tyrrell (1969). The transducers used are Statham force transducers model UC-3 Gold Cell (Universal transducing cell). For measurement of the force of the tetanic contraction of the adductor pollicis muscle a load cell model UL 4-20 has been combined with the transducer to give a linear response for forces up to $9.1 \mathrm{~kg}$ sufficient for the purpose. In the case of the single twitch response a load cell UL $4-5$ has been used and this combined with the transducer produces a linear response for forces up to $2.3 \mathrm{~kg}$ which is adequate for the measurement of the single twitch response.

Basically the transducer is an unbonded straingauge which employs Statham's patented zero-length principle. Very little force or displacement is needed to activate the unbonded strain-sensitive filaments, a characteristic which is particularly appropriate for the measurement of the adduction force of the thumb in almost isometric conditions. A handle has been incorporated round the shaft of the transducer container and a suitably shaped thumb rest attached to the load cell connected to the sensitive tip of the tranducer. When tested the frequency response was flat over the range $0-90 \mathrm{~Hz}$. The transducer is placed in the palm of the hand with the fingers grasping the hand-grip and the thumb mounted on the thumb rest in the extended position to provide a pre-load to the adductor pollicis muscle. The unit is held in position by adhesive tape.

Platinum needle electrodes are then inserted subcutaneously close to the ulnar nerve at the wrist about $20 \mathrm{~mm}$ apart. The electrodes are autoclaved before use and the skin suitably sterilised before insertion. The nerve is stimulated by means of a Devices stimulator type 3072 with an isolation unit and a digitimer type 3290 . The tetanic stimulation is generated in conjunction with a gated pulse generator type 2521 which can produce repetitive stimulation and single pulse stimulation simultaneously and synchronously. One nerve is stimulated tetanically and the other with a single pulse. Usually the tetanic stimulus is applied at $12 \mathrm{~s}$ intervals for one second at a frequency of $50 \mathrm{~Hz}$ with individual pulses lasting for $200 \mu$ s. A supramaximal stimulus is used and the voltage is normally of the order of 20 to 30 volts. The twitch stimulus also supramaximal is a single square wave pulse of $200 \mu \mathrm{s}$ duration applied synchronously with the tetanus at 12 s intervals at 30 to 40 volts. A tetanic stimulus of $50 \mathrm{~Hz}$ was selected because tetanic fusion of the adductor pollicis muscle occurs with frequencies of $35 \mathrm{~Hz}$ and a frequency of $50 \mathrm{~Hz}$ is within the physiological range and so provides tetanic responses without causing undue fatigue.

When the ulnar nerve is stimulated at the wrist in the way described the stimulus affects the adductor pollicis, the deep head of the flexor pollicis brevis, all the interossei and the palmaris brevis muscles. However with the fingers firmly fixed on the handgrip of the transducer most of the muscle activity acts to stabilise the hand and the movement of thumb adduction can be regarded as an isometric contraction of the adductor pollicis. For the purpose of analysis the contractions are recorded on charts at two different speeds. A fast recording is made at a speed of $5 \mathrm{~mm}$ per second on a Mingograf ink-jet recorder with a frequency response up to $500 \mathrm{~Hz}$. At this speed it is possible to follow the pattern of the tetanic contraction, including the element of fade, the radial arterial pressure and the electrocardiogram which are recorded simultaneously. The slow recording of the tetanic and single twitch contractions are made on a Brush Clevite recorder or similar instrument at a chart speed of $5 \mathrm{~mm} / \mathrm{min}$ to illustrate the overall pattern of the responses. The contour of the tetanic contraction is analysed from the fast record and special attention is paid to the peak height as an expression of tetanic transmission and the tetanic fade expressed as the tetanic-tension ratio. The tetanic-tension ratio is defined as the percentage of the amplitude of the tetanic contraction at the end of each one-second burst of tetanic stimulation compared with the initial peak amplitude of the tetanic contraction (de Jong \& Freund, 1967). In the control state the tetanus is well maintained and the tetanic-tension ratio is virtually $100 \%$.

Such analyses are tedious, time-consuming and relatively inaccurate. Fortunately the data lend themselves to computer handling on-line in real-time and a suitable computer program as shown in Figure 1 has been described for the purpose (Perry, Worsley, Sugai \& Payne, 1975). The program allows the online real-time analysis of a range of variables including twitch height, maximum slope of the twitch and twitch pulse widths, peak height of tetanic contraction, end height of tetanic contraction, the tetanic-tension ratio and the percentage tetanic transmission. The program has been used to study the pattern of action of neuromuscular blocking drugs and similar programs have particular value in the assessment of pharmacokinetic activity. 


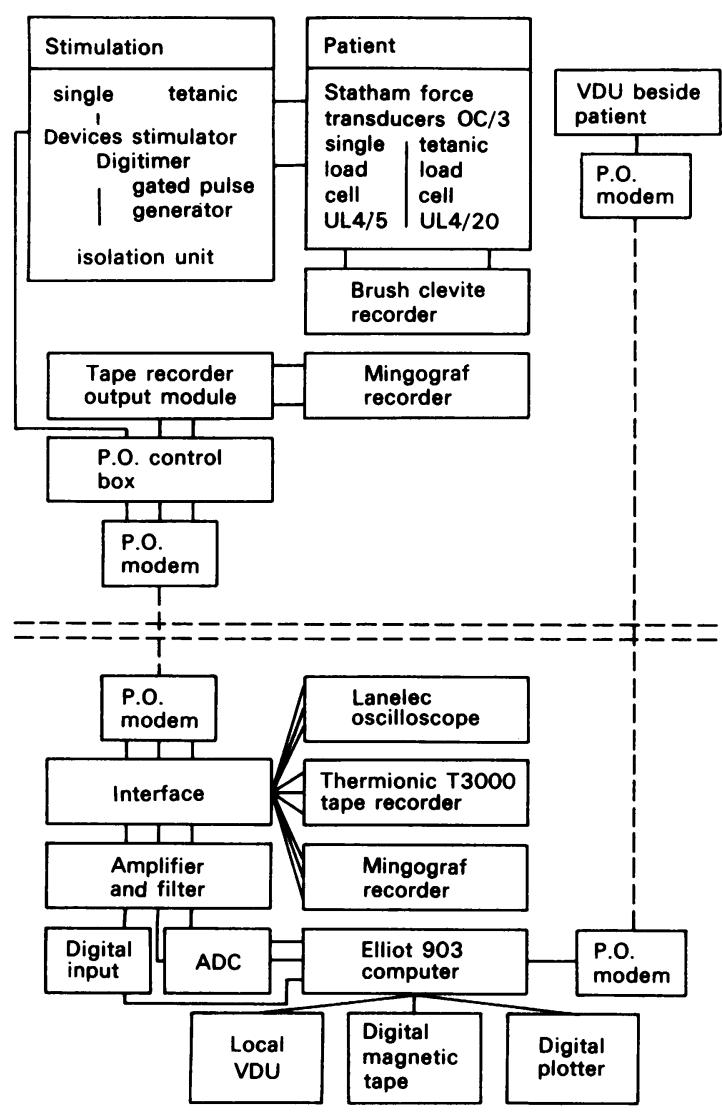

Figure 1 Schematic diagram of the arrangements for the computer analysis of neuromuscular blockade.

The advantages of the tetanic response over the single twitch can be exemplified by simultaneous recordings obtained in three different situations. First, the onset of full block of the tetanic response is more rapid than that of the single twitch so that intubation can be accomplished as soon as the tetanic contractions have disappeared (Figure 2). Second, exposure to $1-2 \%$ halothane during recovery from competitive neuromuscular block enhances blockade of the tetanic response and re-establishes fade, whereas the single twitch is unaffected (Figure 3 ). Thus an assessment based on the single twitch response would not have revealed this effect. Third, in patients given neostigmine the tetanic response revealed the drug's known neuromuscular action as manifested by reduced peak contractions and marked tetanic fade, which persisted for up to $20 \mathrm{~min}$. In contrast no evidence of block was shown by the single twitch contractions which in fact were augmented by neostigmine. Further a sub-paralysing dose of gallamine antagonised the tetanic block and reversed the augmentation of the single twitch (Figure 4).

\section{Electromyography}

Despite the expressed preference of most research workers for the recording of evoked mechanical activity in the study of neuromuscular events there are others who favour the use of the compound muscle action potential.

One of the earliest uses of electromyography for the assessment of neuromuscular blocking drugs was made by Churchill-Davidson \& Richardson (1952) who measured hypothenar muscle activity in the hand to evaluate the action of decamethonium. For measurement of muscle power the ulnar nerve was stimulated supramaximally at the wrist or elbow and the total muscle action potential detected with skin electrodes held in position by suction and contact made with electrode jelly. The action potential was displayed on an oscilloscope after suitable amplification and photographed for subsequent measurement of height of the response. Results were expressed as a percentage of the control and plotted accordingly.

A similar approach was adopted by Desmedt (1962) who has used electromyography extensively in his studies of neuromyopathies but who has reservations about restricting his work to electromyographic measurements and argued that it was essential for the proper study of neuromuscular disorders that evoked electrical and mechanical responses should be recorded simultaneously. Similar reservations were expressed by Katz (1965) who carried out a comparison of electrical and mechanical recording of spontaneous and evoked muscle activity and concluded that the mechanical response to muscle stimulation offered the most satisfactory means of assessing neuromuscular block. But it should be noted that in this particular study the mechanical activity of the small muscles of the hand were being compared with the integrated electromyogram of the oblique-transversus group of abdominal muscles.

This view was not shared by de Jong \& Freund (1967) who were of the opinion that in testing for neuromuscular function EMG and muscle tensions could be used interchangeably. Subsequently Katz seemed to modify his attitude when he chose to study the effects of suxamethonium and tubocurarine on various muscle responses by means of electromyographic and mechanical methods which he described in detail (Katz, 1973). In this study he noted that the presence or absence and magnitude of fade and posttetanic potentiation depended, among other factors, on whether electrical or mechanical responses were used for the assessment but nevertheless by recording both, certain clear differentiations could be made.

Further support for the use of electromyographic techniques has come from Epstein and his colleagues on the grounds that electromyography avoids the difficulties encountered with mechanical recordings 

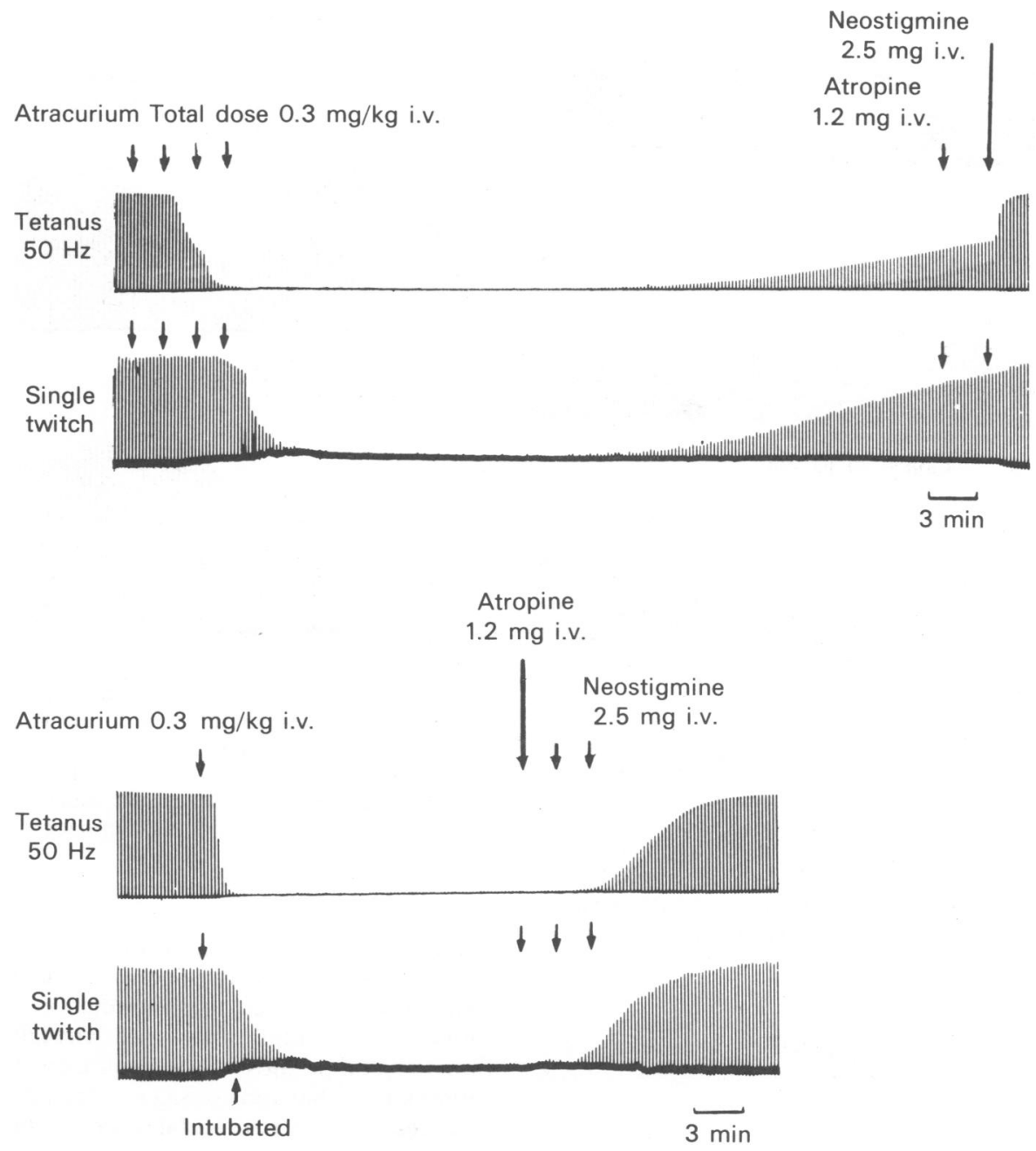

Figure 2 Recordings of the tetanic and single twitch responses of the adductor pollicis muscle from two anaesthetized patients who received atracurium in divided and single doses. Top tracings show rapid antagonism by neostigmine when recovery of tetanic response had reached $50 \%$. Lower tracings show that intubation was accomplished within 2 min of administration of atracurium, 20 min later, complete block was reversed by neostigmine.

such as the proper direction of the force, the variations in loading and the effects of small changes in the angle of the force as well as problems of obtaining a constant resting tension and a true isometric system. In addition electromyographic techniques allow a large number of motor units to be sampled with either surface or bare needle electrodes and maintenance of a constant EMG waveform has not been a problem (Epstein \& Epstein, 1973). Further- more the inconvenience of having to photograph oscilloscope tracings can be avoided by making use of a specially developed recording system for which is claimed the advantages of faithful reproduction of high speed events, ease of use, economy of material and accessibility of large amounts of data (Epstein, Epstein \& Lee, 1973).

It is probably true that in the hands of experts the EMG offers certain advantages but in the absence of 


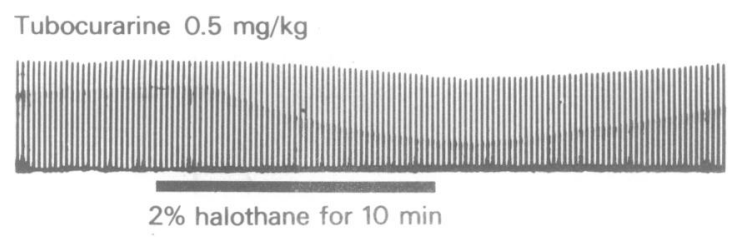

Dimethyl tubocurarine $0.1 \mathrm{mg} / \mathrm{kg}$

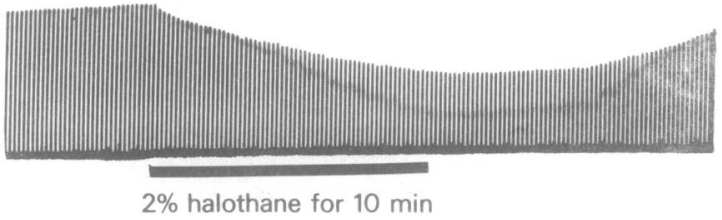

Gallamine $0.8 \mathrm{mg} / \mathrm{kg}$

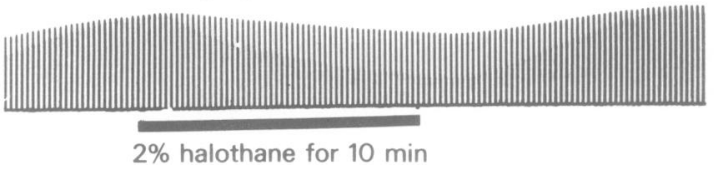

Figure 3 Tracings from three anaesthetized patients showing the tetanic responses of the adductor pollicis muscles during recovery from neuromuscular blockade by tubocurarine, dimethyl tubocurarine and gallamine. Administration of $2 \%$ halothane for 10 min (solid bar line) caused an increase in fade (seen as the lighter lines) with a reduction in the peak height of the tetanic contraction. The effects were reversed when the halothane was turned off.

special expertise most workers will continue to rely on mechanical recordings of the indirectly evoked muscle contraction.

\section{Factors influencing the action of neuromuscular blocking agents}

It is important from the point of view of patient safety that the factors which may modify the action of neuromuscular blocking drugs are properly understood since the lack of such knowledge could lead to operative and post-operative complications.

\section{Route of administration}

An important factor in the quantitative assessment of these drugs is the route of administration which may influence the intensity and duration of the response. For example, the more rapid the intravenous administration of a given dose the greater the intensity of the effect (Foldes, 1957). Furthermore after repeated administration of suxamethonium and decamethonium, tachyphylaxis may develop as manifested

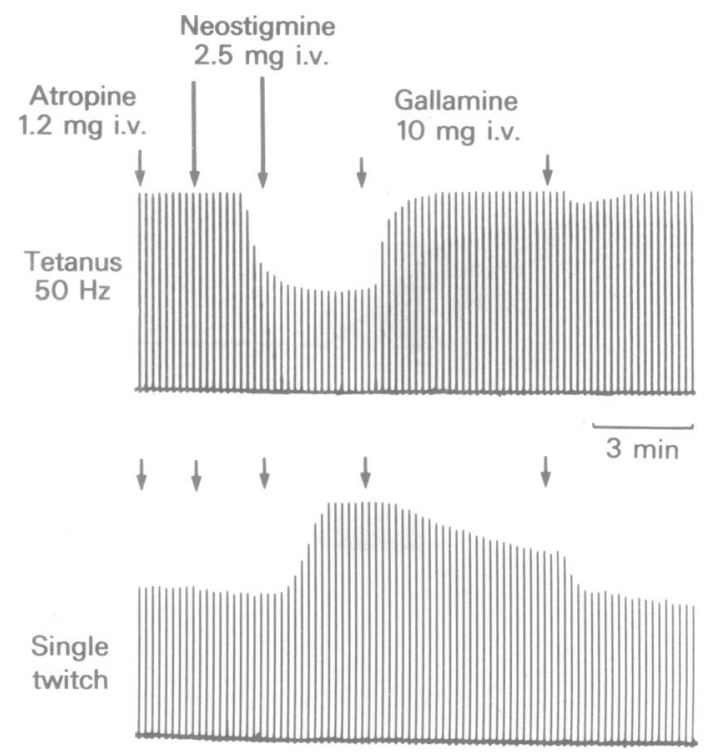

Figure 4 Tracings from an anaesthetized patient showing neuromuscular block of the tetanic response after two doses of neostigmine preceded by atropine and the potentiation of the single twitch. Gallamine antagonized the neuromuscular block of the tetanic response and reversed the potentiation of the single twitch.

by a progressively diminishing effect. In contrast competitive blocking agents usually show an enhanced effect due to accumulation. Since neuromuscular blocking drugs are virtually all highly ionised compounds absorption through the gut is minimal so that oral dosage is excluded. Although theoretically any parenteral route of administration is acceptable, a drug under investigation is usually given intravenously either as a single bolus or as a continuous infusion especially if the drug is a short acting agent like suxamethonium. An alternative approach is to use the divided dose technique now widely exploited and which has proved particularly useful in the study of the onset of action of the new blocking drug atracurium (Payne \& Hughes, 1981).

\section{Variations in sensitivity}

Another factor is the variation in sensitivity to specific neuromuscular blocking agents that occurs between different muscles, and conversely the variation in response of the same muscles to different drugs, and the position is further complicated by species difference. It is therefore of fundamental importance to ensure that when neuromuscular blocking drugs are being studied such variations are fully recognised and they have in fact been widely studied. Paton \& Zaimis 
(1950) reported that the tibialis, a 'white' muscle was more sensitive to decamethonium than the soleus, diaphragm or intercostal muscles, all 'red' muscles. Conversely, the tibialis muscle is less sensitive than the soleus muscle and the diaphragm to tubocurarine (Paton \& Zaimis, 1951; Jewell \& Zaimis, 1954). However Alderson \& Maclagan (1964) found that the difference in sensitivity between the diaphragm and tibialis muscles would be considerably reduced by abolishing the temperature difference which normally exists between the warmer diaphragm muscle and the cooler limb muscles.

\section{Temperature}

Lowering of muscle temperature increases the magnitude of a depolarising block and prolongs its action. In contrast cooling reduces the magnitude of the block produced by competitive agents but leaves the duration of the block almost unaltered (Bigland, Goetzee, Maclagan \& Zaimis, 1958; Cannard \& Zaimis, 1959; Alderson \& Maclagan, 1964). An increase in the effectiveness of acetylcholine could explain the action of cooling on both types of block. Repolarisation of the post-synaptic membrane following the action of acetylcholine may be slowed by cooling (Bigland et al., 1958). Such an action would enhance the paralysing effect of depolarising agents but reduce that of the competitive blockers. Based on these findings it is clear that the temperature of muscles should be maintained at body temperature $\left(37^{\circ} \mathrm{C}\right)$ during the assessment of neuromuscular function.

\section{Rate of stimulation}

During monitoring of neuromuscular transmission the rate of stimulation is an important consideration since the frequency of stimulation increases the intensity of block both by depolarising and competitive agents (Preston \& Van Maanan, 1953; Wislicki 1958). In this context tetanic stimulation is preferable to single twitch stimulation since with tetanus the acetylcholine is fully mobilised as it is released and any prejunctional effects are reflected in the degree of tetanic fade. The single twitch response is inadequate for this purpose since the amount of acetylcholine released is greatly in excess of that required for neuromuscular transmission and Paton \& Waud (1967) have shown that before neuromuscular block of the single twitch becomes apparent the drug must occupy about $80 \%$ of the cholinergic receptors.

\section{Acid-base balance}

Experiments performed to investigate the effects of changes in acid-base balance on neuromuscular blockade have given conflicting results which are probably due to the widely differing experimental techniques employed. In general, neuromuscular blockade by tubocurarine is enhanced by acidosis but antagonised by alkalosis (Maclagan, 1976). Effects on dimethyl tubocurarine, gallamine, alcuronium, suxamethonium and decamethonium appear to be altered in the opposite direction. Various explanations are given for these differences including such factors as changes in muscle blood flow, drug distribution and ionization of the drug and the receptors. More recently, Hughes \& Chapple (1980) have demonstrated that the non-enzymic inactivation of a novel competitive blocking agent atracurium is increased by raising the plasma $\mathrm{pH}$ and there is some evidence this may also be true in anaesthetised man (Payne \& Hughes, 1981).

\section{Drug interactions}

In recent years more information has become available on the interaction of neuromuscular blocking agents with other drugs used in the treatment of surgical patients. Theoretically the simplest interaction at the myoneural receptor is the ability of anticholinesterase compounds such as neostigmine to reverse the competitive blocking action of drugs like curare. In this instance neostigmine acts by combining with the enzyme cholinesterase to prevent it destroying the acetylcholine released at the nerve endings. The accumulation of acetylcholine in turn competes with tubocurarine and similar drugs to displace them from the receptor site. In practice the situation is more complicated; first, the response is related to the existing degree of neuromuscular block and second, it is dose dependent. Thus it is possible to enhance rather than to antagonise the block and it may well be that the so-called neostigmine resistant curarisation occasionally reported in the postoperative period is in fact a neostigmine induced neuromuscular block. The fact that neostigmine and similar drugs can cause neuromuscular block has been known for many years (Briscoe, 1936, 1937; Brennan, 1956) but it is only recently that it has been highlighted in man (Payne, Hughes \& Al-Azawi, 1980).

Again the principles have been well established that depolarising and competitive neuromuscular blocking agents are mutually antagonistic and that anticholinesterase drugs will not antagonise neuromuscular block caused by depolarising drugs. In practice however it can be shown that after repeated doses of suxamethonium and decamethonium, neostigmine and edrophonium will restore normal transmission at the neuromuscular junction. This alteration in response is presumably related to the change in pattern of neuromuscular block that has been demonstrated repeatedly with the depolarising blocking drugs. Apart from the development of tachyphy- 
laxis which may be a component of the changing response it is clear that after repeated doses of suxamethonium and decamethonium the behaviour of the response becomes more readily identified with the pattern of competitive block. Neostigmine block itself must be classified as a depolarising block as witnessed by its enhancement by suxamethonium and its antagonism by gallamine. Of further interest is the prolongation of the block after suxamethonium the duration of which may be extended beyond thirty minutes (Payne et al., 1980).

The matter is further complicated by the fact that general anaesthetics like ether (Paton \& Zaimis, 1951) and halothane (Miller, Way, Dolan, Stevens \& Eger, 1972; Hughes \& Payne, 1979) significantly enhance the effect of neuromuscular block with competitive blocking agents. Furthermore intravenous agents such as thiopentone and diazepam have a potentiating effect on the same agents and in the case of thiopentone this action may be added to the non-specific muscle relaxant properties of the drug, a property that was once frequently used by anaesthetists to obtain profound relaxation for short periods for example for the closing of the peritoneum.

Of clinical importance is the interaction of the aminoglycoside antibiotics with neuromuscular blocking agents (Pittinger \& Adamson, 1972). The mechanism of action has not been clearly defined but a mixture of competitive and depolarising block is often seen with the result that the response to neostigmine is scarcely predictable. There is some evidence that these antibiotics act both by competition and by reducing or preventing the release of acetylcholine an action similar to that of magnesium. The similarity to magnesium is further emphasised by the fact that calcium ions which antagonise the action of magnesium can also relieve antibiotic paralysis.

\section{Genetic deficiencies}

Apart from drug interactions certain genetic deficiencies and some disease states may distort the normal response to neuromuscular blocking drugs. Of the genetic disturbances an abnormally low cholinesterase activity may manifest itself as a prolonged apnoea in response to a normal dose of suxamethonium. Three genetically determined cholinesterases have now been described on the basis of the dibucaine (cinchocaine) inhibition test which measures the ability of dibucaine to inhibit serum cholinesterase activity. The first represents normal individuals in whom $80 \%$ of the activity of their serum cholinesterase is inhibited. In $3 \%$ of the population who form the second group about $62 \%$ inhibition occurs and in the third group, probably about 1 in 5,000 of the population the inhibition of the serum cholinesterase does not exceed $16 \%$. It is this third group who give rise to the clinical problem of prolonged apnoea after suxamethonium although the condition may also be seen in patients with liver disease or dietary deficiency.

A second genetic disturbance even more important to the anaesthetist because of its high mortality is a metabolic disorder of unknown aetiology which gives rise to malignant hyperthermia. The syndrome which has been described in pigs as well as in man is usually triggered by some external factor such as stress or a high environmental temperature. However the commonest triggering agents are general anaesthetics and neuromuscular blocking drugs and the first indication of trouble may be the development of prolonged muscle rigidity rather than the usual relaxation after suxamethonium has been used for intubation. The disturbance is familial and thought to be an autosomal dominant myopathy. Identification of potential victims is difficult but a family history of anaesthetic problems should arouse suspicion. Serum creatine phosphokinase levels may be elevated in susceptible patients and some show an increased incidence of short duration polyphasic action potentials on routine electromyography.

\section{Disease states}

The classical disease state associated with skeletal muscle relaxation is myasthenia gravis and much of the current understanding of the disease mechanisms can be attributed to the accumulated experience of neuromuscular block with depolarising and competitive blocking agents. In particular the resistance of myasthenic patients to large doses of decamethonium contrasts markedly with their susceptibility to small doses of tubocurarine (Churchill-Davidson \& Richardson, 1952). This difference in the response to depolarising and competitive blocking agents has formed the basis not only for diagnostic tests to confirm the presence of the disease but also for its routine management with neostigmine and atropine. It has also helped to define more accurately the site of the disease process. Results obtained from electrophysiological studies on myasthenic patients show that the action potentials and muscle contractions gradually wane during repetitive excitation and that if a brief tetanus is applied the muscles exhibit a characteristic post-activation exhaustion when single test shocks are given at short intervals. This pattern is almost identical with that obtained from muscles treated with hemicholinium which causes a reduction in the amount of acetylcholine released at nerve endings. This suggests that some disturbance of the normal pre-synaptic mechanisms is a fundamental component of the disease.

A syndrome of readily induced fatigue and progressive muscle weakness similar to that found in myasthenic patients has been observed in patients 
with malignant disease particularly that of the lung Such patients are equally sensitive to tubocurarine but unlike those with myasthenia gravis they may also be sensitive to depolarising drugs. This sensitivity may be reversed by anticholinesterases which however have little effect on the muscle weakness itself. The condition usually improves once the malignancy has been removed much in the same way as the myasthenic patient sometimes responds to thymectomy.

A third group of patients with a marked change in sensitivity need to be remembered. Electromyographic studies have shown that premature and newborn babies have a pattern of neuromuscular transmission not unlike that seen in myasthenic patients. These infants, who are very sensitive to tubocurarine, tolerate very large doses of suxamethonium and when block does occur it can be reversed by anticholinesterases.

Finally there is a wide range of myopathic and neurogenic diseases as well as some endocrine disturbances that may give rise to abnormal and often unpredictable responses to neuromuscular blocking drugs. No specific tests are available to determine the pattern of response to be expected when particular neuromuscular blocking drugs are used in such patients.

\section{Conclusion}

The outstanding feature of any scrutiny of the literature of neuromuscular block is the obvious conflict of opinion that exists about almost every aspect of neuromuscular transmission. This is all the more remarkable since the neuromuscular junction is a fairly circumscribed physiological unit which has been well defined and the differences can probably be related to the lack of uniformity in the methods of assessment used by different investigators. The problem is that attempts have been made to interpret events on the basis of results obtained either by different methods of study or by the same method but under different conditions. For example, electromyographic and mechanical methods of assessment do not measure the same variable and even when purely mechanical techniques are used there may be quantitative and qualitative differences between the single twitch and the tetanic response. Furthermore the restriction of the investigation to one particular technique will not necessarily resolve the problem. In the case of tetanic stimuli the pattern of the response will vary with such factors as the frequency of the stimulation and the duration of its application.

Ideally what is needed in the assessment of neuromuscular block is agreement between workers in the field about a uniform pattern of investigation to be applied in all studies of new drugs, and the technology and the expertise are now available to provide completely standardised methods. Where investigators believe that a different approach might offer certain advantages the new approach should be compared with the standard methods. In the absence of such agreement editors of scientific journals should ensure that authors provide enough detail about their methods to allow other workers to repeat experiments which purport to show patterns of drug action that differ from the accepted response.

\section{References}

ALDERSON, A.M. \& MACLAGAN, J. (1964). The action of decamethonium and tubocurarine on the respiratory and limb muscle of the cat. J. Physiol. (Lond.), 173, 38-56.

ALI, H.H., UTTING, J.E. \& GRAY, C. (1970). Stimulus frequency in the detection of neuromuscular block in humans. Br. J. Anaesth., 42, 967-978.

BERNARD, C. (1851). Action de Curare et de la Nicotine sur le systeme Nerveux et sur le systeme Musculaire. Compt. rend. Soc. Biol., 2, 195.

BENNETT, A.E. (1941). Curare: a preventive of traumatic complications in convulsive shock therapy. Am. J. Psychiat., 97, 1040-1060.

BIGLAND, B., GOETZEE, B., MACLAGAN, J. \& ZAIMIS, E. (1958). The effect of lowered muscle temperature on the action of neuromuscular blocking drugs. J. Physiol. (Lond.), 141, 425-434.

BIGLAND, B. \& LIPPOLD, O.C.J. (1954). Motor unit activity in the voluntary contraction of human muscle. $J$. Physiol. (Lond.), 125, 322-335.
BODMAN, R.I. (1952). Evaluation of two synthetic curarizing agents in conscious volunteers. Br. J. Pharmac. Chemother. , 7, 409-416.

BRENNAN, H.J. (1956). Dual action of suxamethonium chloride. Br. J. Anaesth., 28, 159-168.

BRISCOE, G. (1936). Shift in optimum rate of stimulation due to prostigmine. J. Physiol. (Lond.), 86, 48P.

BRISCOE, G. (1937). Optimum stimulation rates for red and white skeletal mammalian muscles, and shift in rates produced by the eserine group. J. Physiol. (Lond.), 90, $10 \mathrm{P}$.

CANNARD, T.H. \& ZAIMIS, E. (1959). The effect of lowered muscle temperature on the action of neuromuscular blocking drugs in man. J. Physiol. (Lond.), 149, 112-119.

CHURCHILL-DAVIDSON, H.C. \& RICHARDSON, A.T (1952). Decamethonium iodide (C 10): some observations on its action using electromyography. Proc. Roy. Soc. Med., 45, 179-185.

COOKSON, J.C. \& PATON, W.D.M. (1969). Mechanisms of 
neuromuscular block. Anaesthesia, 24, 395-416.

DALE, H.H. \& FELDBERG, W. (1934). The chemical transmission of secretory impulses to the sweat glands of the cat. J. Physiol., 82, 121-128.

DALE, H.H., FELDBERG, W. \& VOGT, M. (1936). Release of acetylcholine at voluntary motor nerve endings. $J$. Physiol. , 86, 353-380.

DE JONG, R.H. \& FREUND, F.G. (1967). Characteristics of the neuromuscular block with succinylcholine and decamethonium in man. Anesthesiology, 28, 583-591.

DESMEDT, J.E. (1962). Donnees recentes sur la pathogenie de la myasthenie grave. Bull. de l'Academie Royale de Medicine de Belgique, 7, 213-267.

EPSTEIN, R.M., EPSTEIN, R.A. \& LEE, A.S.J. (1973). A recording system for continuous evoked electromyography. Anesthesiology, 38, 287-289.

EPSTEIN, R.A. \& EPSTEIN, R.M. (1973). The electromyogram and the mechanical response of indirectly stimulated muscle in anaesthetized man following curarization. Anesthesiology, 38, 212-223.

FOLDES, F.F. (1957). Fate of muscle relaxants in man. Acta anaesth. Scand., 1, 63-79.

GISSEN, A.J. \& KATZ, R.L. (1969). Twitch, tetanus and post-tetanic potentiation as indices of nerve-muscle block in man. Anesthesiology, 30, 481-487.

GRIFFITH, H.R. \& JOHNSON, G.E. (1942). The use of curare in general anaesthesia. Anesthesiology, 3, 418-420.

HUGHES, R. \& CHAPPLE, D.J. (1980). Experimental studies with atracurium, a new neuromuscular blocking agent. Br. J. Anaesth., 52, 238P.

HUGHES, R. \& PAYNE, J.P. (1979). Interaction of halothane with non-depolarizing neuromuscular blocking drugs in man. Br. J. clin. Pharmac., 7, 485-490.

JEWELL, P.A.. \& ZAIMIS, E. (1954). A differentiation between red and white muscle in the cat based on responses to neuromuscular blocking agent. J. Physiol. (Lond.), 124, 417-428.

JOHANSEN, S.H., JORGENSEN, M. \& MOLBECH, S. (1964). Effect of tubocurarine on respiratory and nonrespiratory muscle power in man. J. appl. Physiol., 19, 990-994.

KATZ, R.L. (1965). Comparison of electrical and mechanical recording of spontaneous and evoked muscle activity. Anesthesiology, 26, 204-221.

KATZ, R.L. (1973). Electromyographic and mechanical effects of suxamethonium and tubocurarine on twitch, tetanic and post-tetanic responses. Br. J. Anaesth., 45, 849-859.

MACLAGAN, J. (1976). Competitive neuromuscular blocking drugs. In Neuromuscular Junction. ed Zaimis, E., pp 462-467 Berlin: Springer-Verlag.

MAPLESON, W.W. \& MUSHIN, W.W. (1955). Relaxant action in man. Anaesthesia, 10, 265-278.

MILLER, R.D., WAY, W.L., DOLAN, W.M., STEVENS, W.C. \& EGER, E.I. (1972). The dependence of pancuronium and d-tubocurarine-induced neuromuscular blockades on alveolar concentrations of halothane and Forane. Anesthesiology, 37, 573-581.
MUSHIN, W.W., WIEN, R., MASON, D.F.J. \& LANGSTON, G.T. (1949). Curare-like actions of tri-(diethylaminoethoxy) benzene triethyliodide. Lancet, i, 726-728.

ORGANE, G., PATON, W.D.M. \& ZAIMIS, E.J. (1949). Preliminary trials of bistrimethyl ammonium decane and pentane diiodide (C.10 and C.5) in man. Lancet, i, 21-23.

PATON, W.D.M. \& WAUD, D.R. (1967). The margin of safety of neuromuscular transmission. J. Physiol., 191, 59-90.

PATON, W.D.M. \& ZAIMIS, E.J. (1948). Clinical potentialities of certain bisquaternary salts causing neuromuscular and ganglionic block. Nature, 162, 810 .

PATON, W.D.M. \& ZAIMIS, E.J. (1950). Actions and clinical assessment of drugs which produce neuromuscular block. Lancet, ii, 568-570.

PATON, W.D.M. \& ZAIMIS, E.J. (1951). The action of dtubocurarine and of decamethonium on respiratory and other muscles in the cat. J. Physiol. (Lond.), 112, 311-331.

PAYNE, J.P. \& HOLMDAHL, M.H. (1959). The effect of repeated doses of suxamethonium in man. Br. J. Anaesth., 31, 341-347.

PAYNE, J.P. \& HUGHES, R. (1981). Evaluation of atracurium in anaesthetized man. Br. J. Anaesth., 53, 45-54.

PAYNE, J.P., HUGHES, R. \& AL-AZAWI, S. (1980).Neuromuscular blockade by neostigmine in anaesthetized man. Br. J. Anaesth., 52, 69-76.

PERRY, I.R., WORSLEY, R., SUGAI, N. \& PAYNE, J.P. (1975). The use of a digital computer for the on-line real-time assessment of neuromuscular blockade in anaesthetized man. Br. J. Anaesth., 47, 1097-1100.

PITTINGER, C. \& ADAMSON, R. (1972). Antibiotic blockade of neuromuscular function. Pharmac. Rev., 12, 169-184.

POULSEN, H. \& HOUGS, W. (1957). The effect of some curarizing drugs in unanaesthetized man, 1. Acta anaesth. Scand., 1, 15-39.

PRESTON, J.B. \& VAN MAANAN, E.F. (1953). Effects of frequency of stimulation on the paralysing dose of neuromuscular blocking agents. J. Pharmac. exp. Ther., 107, 165-171.

ROBERTS, D.V. \& WILSON, A. (1969). Physiology of neuromuscular transmission. In Electromyography in diagnosis and treatment of myasthenia gravis, ed Green, R., pp 14-19. London: William Heinemann.

SUGAI, N., HUGHES, R. \& PAYNE, J.P. (1973). The use of tetanic and single twitch stimuli to assess neuromuscular block in man. Br. J. Anaesth., 45, 642-643.

THESLEFF, S. (1952). An investigation of the musclerelaxing action of succinyl-choline-iodide in man. Acta physiol. Scand., 25, 348-367.

TYRRELL, M.F. (1969). The measurement of the force of thumb adduction. Anesthesia, 24, 626-629.

WEST, R. (1932). Curare in man. Proc. Roy. Soc. Med., 25, 1107-1116.

WISLICKI, L. (1958). Effects of rate of stimulation and of fatigue on the response of neuromuscular blocking agents. Br. J. Pharmac., 13, 138-143. 